\title{
Variability of basic blood parameters in dependence of physiological status in highly productive cows
}

\author{
V.M. Gukezhev ${ }^{1}$, Jh.H. Kurashev ${ }^{1, *}$, M.H. Zhekamukhov ${ }^{1}$, A.G. Genchev ${ }^{3}$, I.Kh. Taov ${ }^{2}$ \\ ${ }^{1}$ Institute of Agriculture of Kabardino-Balkarian Scientific Center of the Russian Academy of \\ Sciences, 360022, KBR, Nalchik, Russia \\ ${ }^{2}$ Kabardino-Balkarian State Agrarian University, 360001, KBR, Nalchik, Russia \\ ${ }^{3}$ Trakia University, Department of 'Animal Husbandry - Monogastric and Other Animals', Poultry \\ Section, Faculty of Agriculture, Stara Zagora, Bulgaria
}

\begin{abstract}
The analysis of hematological parameters of blood was carried out in highly productive cattle of black-and-white Holstein cows of the Netherlands selection on a robotic farm in the steppe zone of KabardinoBalkaria. To establish the influence of physiological status controlled livestock $(n=64)$ was divided into three groups: dry $(n=13)$, fresh and inseminated $(\mathrm{n}=20)$ and pregnant $(\mathrm{n}=31)$. The analysis was conducted for 9 basic blood elements (WBC, Lim, Gran, Mid, RBC, HGB, HCT, $\mathrm{MCH}$ ) with setting the limit of extreme variants and the difference between them, $\mathrm{X} \pm \mathrm{mx}, \sigma, \mathrm{Cv}$ for each group in comparison with the average values for the entire sample. It was found that the grouping of cows makes it possible to differentiate the variability and average indicators of the blood composition taking into account the physiological status. The highest rates were noted in the group of pregnant cows, lower were in the group of just calving and inseminated cows, but had not tested for pregnancy yet. Heifer cow performance was more stable.
\end{abstract}

\section{Introduction}

It is required global changes in the world market for production of milk and dairy products and adopted appropriate measures to ensure the ability to meet the needs of the population in these products [1-3]. In this concern, it is considered the widespread use of the potential of the most highly productive Holstein breed as one of the reserves for increasing milk production. The republic has experience in using this breed [4-6]. So, in the breeding farm of Agro-Soyuz LLC of the Chegem region, the black-and-white Holstein breed has been bred under conditions of loose maintenance of the same type of feeding with milking on a group milking machine "Karusel" for about ten years now with an average milk yield of more than $8500 \mathrm{~kg}$ per cow per year. Nowadays, the process of mastering the robotic technology of livestock maintenance is underway in two farms in the republic, and

\footnotetext{
${ }^{*}$ Corresponding author: kurashev-j@mail.ru
} 
this work is devoted to the study of adaptation process of the Holstein breed of the Netherlands selection to the steppe zone conditions of the South Russia.

Relevance. The use of the gene pool of the Holstein breed is one of the accelerated methods of productivity growth and increasing milk production. In this regard, the study of this breed adaptability to the climatic, forage and technological (robotic farm) conditions of the South of Russia is very important $[7,8]$.

The aim of the investigation is to establish the variability of the main hematological blood parameters depending on the physiological status of highly productive cows as a response to the process of adaptability.

\section{Material and methods}

A sample for hematological analysis was taken from the tail vein in the middle third of 2-5 vertebrae after treatment with alcohol in the early morning before the cows received food. (Fig. 1).

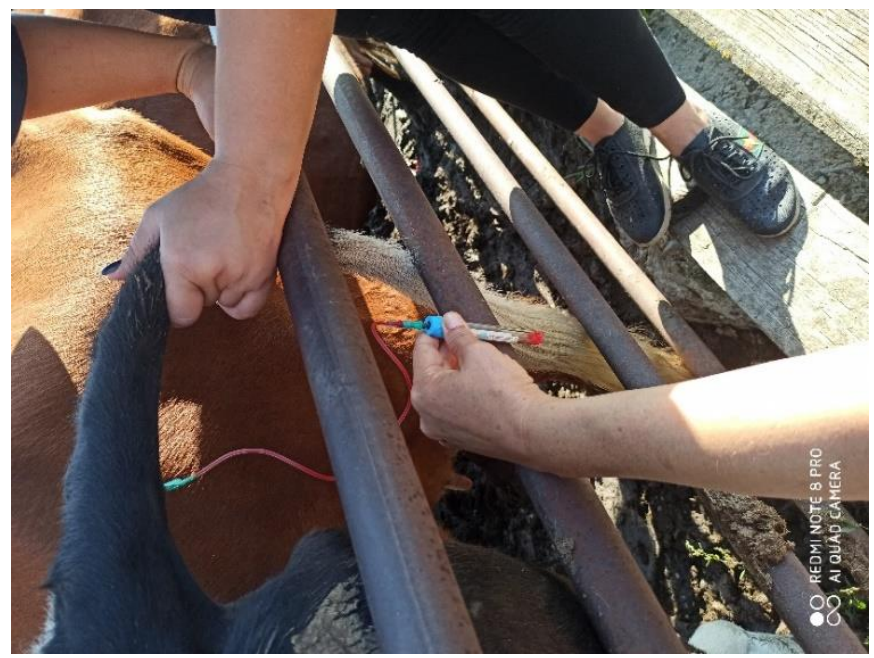

Fig. 1. A method of sampling blood from the tail artery.

This method of blood analyses is in inserting the needle at an angle of 20-300 to the depth of $5 \mathrm{~mm}$, the tip of the syringe should be directed towards the head. It is important to take into account that the blood volume should be at least $5 \mathrm{ml}$ with the anticoagulant $0.5 \mathrm{M}$ EDTA (Fig. 2). 


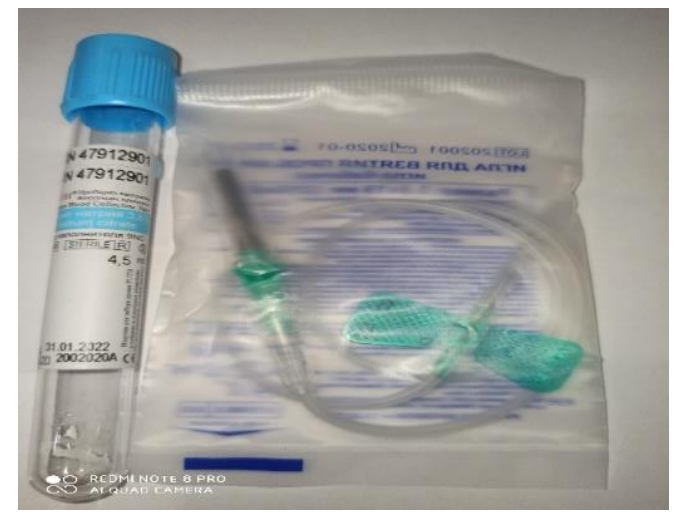

Fig. 2. Stopper with a needle bow

The blood test was carried out on "Hemalight 1270" hematological analyzer according to 9 parameters (Fig. 3).

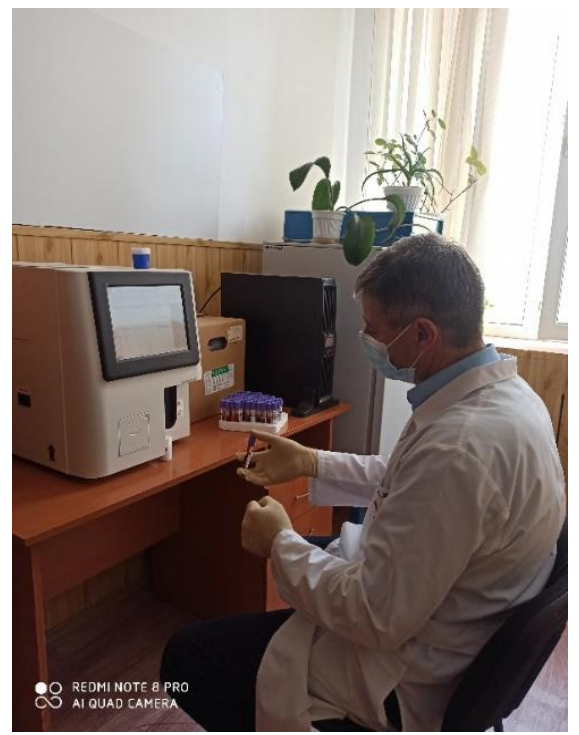

Fig. 3. Analysis on the device "Gemalight 1270"

In general, taking blood from cows is considered a rather traumatic and painful procedure. The work associated with taking blood has been somewhat simplified with the invention of vacuum tubes and syringes for them. It is known from veterinary experience that each treatment of cows, leads to a stressful state, which subsequently affects milk production, including blood sampling from cows.

\section{Research results and discussion}

In accordance with the methodology and purpose of the investigation, the controlled livestock of cows was divided into three groups: heifer, fresh and inseminated, but not 
tested for pregnancy and pregnant in order to establish the influence of the physiological status on the absolute value of hematological blood parameters. It was necessary to find out to what extent the physiological status of animals affects the average value and variability of the main blood components taking into consideration the high variability of indicators.

A comparative assessment of the results obtained (table 1) has a significant effect on the average indicators convincingly indicates the physiological state of animals. The analysis suggests that of all three groups, the most significant effect on both the value of the average indicators and their variability is exerted by the animals' pregnancy. In all likelihood, the onset of pregnancy, united with high milk yield, creates an overloaded peak and is the main cause of sharp fluctuations in virtually all analyzed blood parameters. An interesting fact is that, the maximum value was noted in the group of pregnant cows with the exception of the absolute number of granulocytes (- 2.03), according to all other indicators. At the same time, they also exceeded both average and variability values of the main blood parameters.

The hematological blood parameters of fresh and inseminated cows are below average for most parameters, but not yet tested for pregnancy, respectively, and their variability is also relatively lower. An insignificant and insufficient superiority of this group of animals over the average indicators for the entire sample was noted for the absolute number of granulocytes $(+1.70)$, hemoglobin concentration $(+160)$ and the absolute number of erythrocytes $(+0.17)$.

Careful analysis is required for the conditions of heifer cows. This is the time during which is necessary to stabilize all vital functions of animal body and create a "safety margin" so that the fatness of cows is assessed in the range of at least $3.5-4.0$ points. However, it must be borne in mind that in the last three months of pregnancy, there is an intensive growth of the fetus and overfeeding is fraught with heavy calving, therefore, it is needed differentiated approach to both diets and animals.

According to the results of our investigation, the average indicators of the analyzed blood elements of heifer cows insignificantly and unreliably correspond to the entire sample data, while the variability, with the exception of the absolute number of granulocytes $(+9.54)$, is lower for all indicators, which indicates a certain stabilization of quantitative values.

It should be noted that quite consciously we do not compare the results obtained with the generally accepted norms of hematological indicators of the blood of cattle at this stage, , due to the high variability of a number of individual elements that can be triggered by a significant difference in the natural and climatic conditions of detention, as well as with relatively equal in nutritional value, but somewhat different in the structure of the diet.

It seems more logical to us to establish such norms after at least one generation has changed for imported livestock.

\section{Conclusions}

Based on the results of the investigation, the following main conclusions can be drawn:

- the average hematological blood counts of cows of an individual herd cannot be used as the basis for establishing regional norms for highly productive cows, since they largely neutralize the influence of the physiological status and, depending on the quantitative ratio of cows of different status, can be overestimated or underestimated. 
Table 1. Hematological blood parameters of the Holstein cows

\begin{tabular}{|c|c|c|c|c|c|c|c|c|c|c|}
\hline \multirow[b]{2}{*}{ 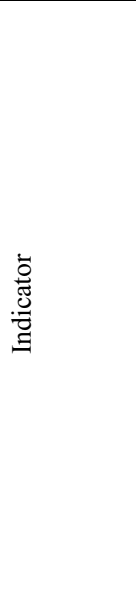 } & \multirow[b]{2}{*}{$\stackrel{7}{\frac{D}{2}}$} & WBC & $\begin{array}{l}\text { LIM } \\
\# \\
\end{array}$ & $\begin{array}{l}\text { GRAN } \\
\#\end{array}$ & MID \% & RBC & HGB & HCT & $\mathrm{MCV}$ & $\mathrm{MCH}$ \\
\hline & & 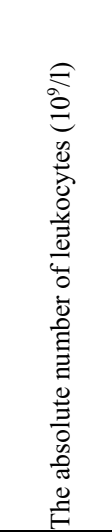 & 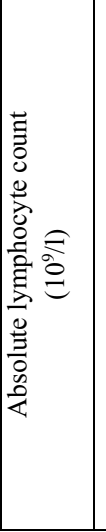 & 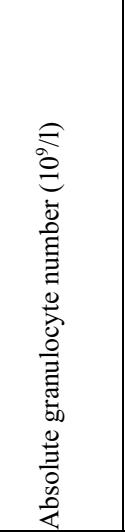 & 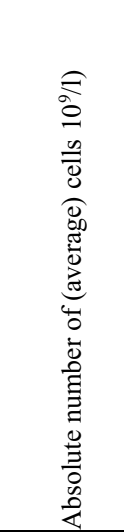 & 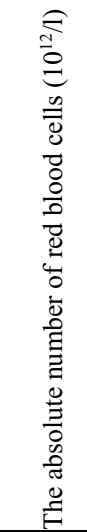 & 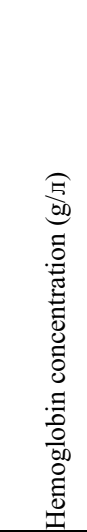 & 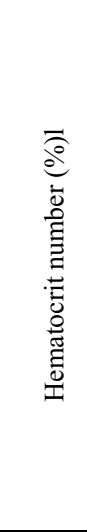 & 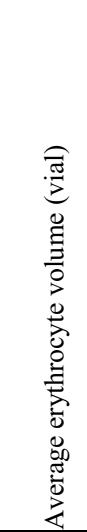 & 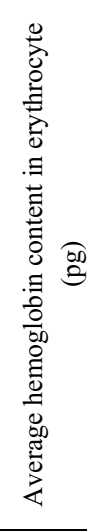 \\
\hline \multicolumn{11}{|c|}{ Average indicators for entire selection $(n=64)$} \\
\hline $\begin{array}{l}\text { Max. } \\
\text { value }\end{array}$ & - & 38,53 & 26,28 & 11,43 & 9,55 & 7,64 & 110,0 & 0,386 & 57,5 & 19,9 \\
\hline Min. value & - & 4,34 & 1,08 & 1,55 & 0,42 & 4,30 & 72,0 & 0,224 & 45,0 & 13,0 \\
\hline Difference & - & 34,19 & 25,2 & 9,88 & 5,13 & 3,34 & 46,0 & 0,162 & 12,5 & 6,9 \\
\hline$\sigma$ & - & 4,85 & 4,16 & 2,08 & 0,80 & 0,74 & 8,69 & 0,030 & 2,62 & 1,32 \\
\hline$\overline{m_{x}}$ & - & 0,55 & 0,477 & 0,238 & 0,02 & 0,08 & 0,99 & 0,003 & 0,300 & 0,152 \\
\hline$\overline{C_{V}}$ & - & 37,76 & 64,29 & 42,47 & 56,50 & 11,78 & 9,06 & 10,54 & 5,32 & 8,74 \\
\hline $\bar{X}$ & - & 12,84 & 6,48 & 4,83 & 1,42 & 6,25 & 99,90 & 0,312 & 49,30 & 15,18 \\
\hline \multicolumn{11}{|c|}{ Heifer $(n=13)$} \\
\hline $\begin{array}{l}\text { Max. } \\
\text { value }\end{array}$ & - & $-15,01$ & $-9,75$ & 0 & $-2,89$ & $-0,27$ & -4 & $\begin{array}{l}- \\
0,009\end{array}$ & $-5,8$ & $-3,4$ \\
\hline Min. value & - & $+4,11$ & $+1,19$ & $+0,20$ & $+0,03$ & $+1,05$ & +14 & $\begin{array}{l}+0,05 \\
1\end{array}$ & $+0,20$ & $+0,3$ \\
\hline Difference & - & $-19,12$ & $\begin{array}{l}- \\
10,94\end{array}$ & $-0,20$ & $-2,92$ & $-1,14$ & -18 & $\begin{array}{l}- \\
0,059\end{array}$ & $-6,0$ & $-3,5$ \\
\hline$\sigma$ & - & $-0,47$ & $-0,41$ & $+0,48$ & $-0,17$ & $-0,17$ & $-1,1$ & $\begin{array}{l}- \\
0,010\end{array}$ & $-0,64$ & $-0,35$ \\
\hline $\mathrm{m}_{\mathrm{x}}$ & - & $+8,71$ & $\begin{array}{l}+0,60 \\
3\end{array}$ & $+0,502$ & $+0,16$ & $+0,08$ & $+1,20$ & $\begin{array}{l}+0,00 \\
4\end{array}$ & $\begin{array}{l}+0,27 \\
0\end{array}$ & $\begin{array}{l}+0,12 \\
8\end{array}$ \\
\hline$\overline{C_{V}}$ & - & $-4,99$ & $\begin{array}{l}- \\
11,40\end{array}$ & $+9,54$ & $-8,25$ & $-2,83$ & $-1,24$ & $-2,24$ & $\begin{array}{l}- \\
1,290\end{array}$ & $-2,24$ \\
\hline $\bar{X}$ & - & $+0,52$ & 0,62 & $+0,05$ & $-0,12$ & $+0,12$ & $+1,02$ & $\begin{array}{l}+0,00 \\
5\end{array}$ & $\begin{array}{l}- \\
0,160\end{array}$ & $-0,18$ \\
\hline \multicolumn{11}{|c|}{ New calved and inseminated, but not tested for pregnancy $(n=20)$} \\
\hline $\begin{array}{l}\text { Max. } \\
\text { value }\end{array}$ & $-8,5$ & $-16,68$ & $\begin{array}{l}- \\
11,86\end{array}$ & $-1,67$ & $-2,60$ & $-0,20$ & 0 & $\begin{array}{l}- \\
0,012\end{array}$ & $-4,80$ & $-2,9$ \\
\hline Min. value & $+11,0$ & 0 & 0 & $-0,17$ & 0 & 0,49 & 5 & 0,008 & 0,07 & 0,1 \\
\hline Difference & $-19,5$ & $-16,65$ & $\begin{array}{l}- \\
11,86\end{array}$ & $-2,04$ & $-2,60$ & $-0,69$ & -5 & $\begin{array}{l}- \\
0,020\end{array}$ & $-5,50$ & $+3,0$ \\
\hline$\sigma$ & $-6,48$ & $-1,03$ & $-0,88$ & $+0,09$ & $-0,17$ & $-0,06$ & $+0,31$ & 0 & $-0,37$ & $-0,14$ \\
\hline $\mathrm{m}_{\mathrm{x}}$ & $+0,20$ & $+0,32$ & $\begin{array}{l}+0,27 \\
3\end{array}$ & $+0,252$ & $+0,12$ & $+0,07$ & $+1,07$ & $\begin{array}{l}+0,00 \\
4\end{array}$ & $+0,21$ & $\begin{array}{l}+0,11 \\
8\end{array}$ \\
\hline$\overline{\mathrm{C}_{\mathrm{V}}}$ & - & $-5,04$ & $-1,69$ & $+0,30$ & $-6,74$ & $-1,26$ & $+0,17$ & $-0,55$ & $-0,72$ & $-0,85$ \\
\hline
\end{tabular}




\begin{tabular}{|l|l|l|l|l|l|l|l|l|l|l|l|}
\hline & 34,54 & & & & & & & & & \\
\hline $\mathbf{X}$ & $+8,14$ & $-1,17$ & $-1,24$ & $+1,70$ & $-0,16$ & $+0,17$ & $+1,60$ & $\begin{array}{l}+0,00 \\
6\end{array}$ & $-0,42$ & $-0,18$ \\
\hline \multicolumn{7}{|c|}{ Pregnant (n= 31) } \\
\hline $\begin{array}{l}\text { Max. } \\
\text { value }\end{array}$ & $-19,2$ & 0 & 0 & $-2,03$ & 0 & 0 & 0 & 0 & 0 & 0 \\
\hline Min. value & $-1,1$ & 1,09 & 0,66 & 0 & 0,25 & 0 & 11 & 0 & 0 & 0 \\
\hline Difference & $-20,3$ & $-1,09$ & $-0,66$ & $-2,03$ & $-0,25$ & 0 & -11 & 0 & 0 & 0 \\
\hline$\sigma$ & $-7,56$ & $+0,69$ & $+0,87$ & $-0,24$ & $+0,15$ & $+0,06$ & $+0,45$ & 0 & $+0,39$ & $+0,23$ \\
\hline $\mathrm{m}_{\mathrm{x}}$ & $-0,34$ & $+0,53$ & $+0,44$ & $+0,092$ & $+0,15$ & $+0,07$ & $+0,45$ & $+0,00$ & $+0,25$ & $+0,12$ \\
\hline $\mathrm{C}_{\mathrm{V}}$ & - & $+5,25$ & $+5,73$ & $-5,69$ & $+2,07$ & $+0,87$ & $+0,69$ & $+0,89$ & $+0,78$ & $+1,42$ \\
\hline $\mathbf{X}$ & 30,11 & & & & & & & & & & \\
\end{tabular}

-grouping of cows according to their physiological status on heifer, freshly bred inseminated, but not yet tested for pregnancy and pregnant cows indicates the presence of certain difference in quantitative and qualitative indicators of the main blood elements both in comparison with the average for the livestock and between groups

- the highest variability of analyzed blood parameters was noted for the pregnant group with insufficient difference in quantitative composition and the minimum for heifer ones, new calved and inseminated were located closer to the heifer ones.

\section{References}

1. V.A. Ermolaev, E.M. Maryin, A.V. Sapozhnikov, P.M. Lyashenko, A.Z. Mukhitov, A.V. Kireev, Hematology (Ulyanovsk, Ulyanovsk State Agricultural Academy named after P.A. Stolypin, 135, 2016)

2. O.O. Getokov, M.I. Uzhakhov, Z.M. Dolgieva, Agrarian Russia, 4, 47-48 (2003)

3. E.V. Gromyko, Ecological Bulletin of the North Caucasus, 2, 80-94 (2005)

4. Yu.V. Sizova, Bulletin of biotechnology, 1, 5-7 (2016)

5. V.B. Leibova, I.Yu. Lebedeva, Achievements of Science and Technology of APK, 10, 45-48 (2011)

6. E.V. Matosova, B.G. Andryukov, Hematology and Transfusiology, 4 (62), 223-229 (2017)

7. G.Ya. Levin, E.G. Sukhareva, Hematology and Transfusiology, 1 (61), 21-24 (2016)

8. N.V. Zubkova, Hematology and Transfusiology, 2(59), 44-49 (2014) 